\title{
The quality of the relationship perceived by spouses of people with young-onset dementia
}

\author{
Jeroen Bruinsma, ${ }^{1}$ Kirsten Peetoom, ${ }^{1}$ Joany Millenaar, ${ }^{2}$ Sebastian Köhler, ${ }^{1}$ \\ Christian Bakker, ${ }^{3,4,5}$ Raymond Koopmans, ${ }^{3,4,6}$ Yolande Pijnenburg, ${ }^{7}$ Frans Verhey, \\ and Marjolein de Vugt ${ }^{1}$
}

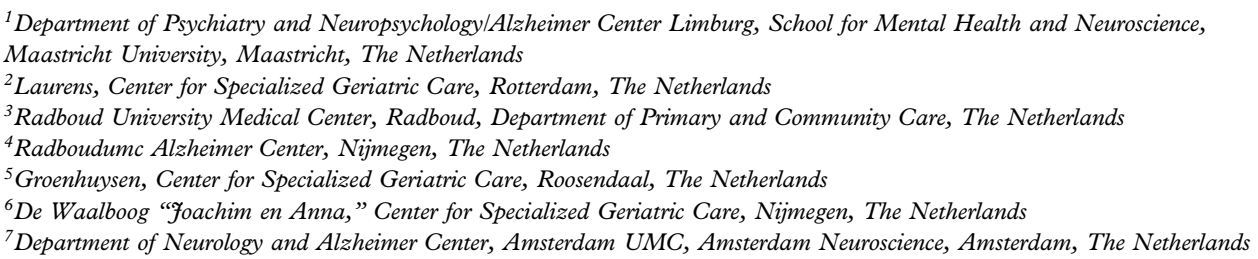

ABSTRACT

Background: Young-onset dementia (YOD) has a profound impact on spouses. However, little is known on how the quality of the relationship changes over time in YOD. This study aims to determine how the quality of the relationship changes over time and identify predictors of this change.

Methods: This study used data from the NEEDs in Young onset Dementia (NeedYD) study. The primary outcome measure was the quality of the relationship perceived by spouses measured throughout 24 months. Baseline characteristics of persons with YOD and spouses were also measured to assess their predictive value.

Results: Totally, 178 dyads were included. The perceived quality of the relationship deteriorated over time. A longer symptom duration, a diagnosis of frontotemporal dementia, lower levels of awareness of deficits, lower levels of initiative toward daily living activities, and higher levels of apathy, hyperactivity, depression, and anxiety in the person with YOD were associated with a lower perceived quality of the relationship by spouses. A coping style characterized by palliative and passive reacting patterns and higher levels of neuroticism in spouses was also associated with a lower quality of the relationship.

Conclusion: The quality of the relationship as perceived by spouses deteriorated over time and was influenced by characteristics of the person with YOD as well as their spouse. Helping spouses to come to terms with factors that threaten their sense of couplehood might help them to develop a more positive attitude toward their spousal relationship and improve the quality of the relationship and care.

Keywords: young-onset dementia, carers, neuropsychiatric symptoms, longitudinal studies, frontotemporal dementia

\section{Introduction}

Young-onset dementia (YOD) is defined as dementia with symptom onset before the age of 65 . The onset of symptoms at a young age can cause specific challenges for spousal caregivers that may impact their perception of the spousal relationship. Having a close and high-quality relationship seems to

Correspondence should be addressed to: Marjolein de Vugt, Department of Psychiatry and Neuropsychology/Alzheimer Center Limburg, School for Mental Health and Neuroscience, Maastricht University, P.O. UNS.40 box 616, Maastricht 6200 MD, The Netherlands. Telephone: + 31 (043) 3877445. Email: m.devugt@maastrichtuniversity.nl. Received 15 Oct 2019; revision requested 23 Dec 2019; revised version received 31 Jan 2020; accepted 18 Feb 2020 . provide people with a sense of security and support and will also have a positive effect on our well-being and quality of life (Vangelisti and Perlman, 2006). Specific challenges that occur due to YOD may affect the quality of the spousal relationship. For example, the prolonged time to diagnosis can be a challenge since early symptoms of YOD are frequently mislabeled as marital problems, burn-out, or depression (Draper and Withall, 2016; van Vliet et al., 2011). Spouses are often confronted with changes in personality and behavior in the person with YOD. Misunderstanding the cause of personality and behavioral change may affect the quality of the relationship (Holdsworth and McCabe, 2018). Spouses are also challenged by a longer period of 
care at home in YOD, and the mean time until institutionalization is reported to be 8.9 years in YOD compared to 4.2 years in late-onset dementia (LOD) (Bakker et al., 2013). This can result in a higher risk of overburden in spouses (van Vliet et al., 2010b).

Previous research has shown that spouses of people with YOD experience changes in the quality of the relationship due to a decline in reciprocity and changes in sexuality (Lockeridge and Simpson, 2013), shifting roles and responsibilities (Massimo et al., 2013), and social isolation (Kimura et al., 2015). Changes in mood, behavior, and daily functioning in the person with YOD may result in feelings of disappointment, anger, and frustration and sometimes result in conflict between spouses (van Vliet et al., 2011). While similar changes have been reported by spouses of people with LOD, the impact of these changes is different in a younger life phase. Spouses of people with YOD often experience increased financial pressure due to a loss of income together with financial responsibilities, such as a mortgage and the education of children (Holdsworth and McCabe, 2018). Although most of these challenges seem to impact the quality of the relationship, some spouses of people with dementia, but not specifically YOD, might still experience high levels of emotional closeness (de Vugt et al., 2003, Riedijk et al., 2008). Indeed, spouses of persons with YOD have reported that they are able to spend more time together and experience a stronger bond (Wawrziczny et al., 2016).

Although YOD has a profound impact on the quality of the relationship, there seems to be a lack of age-appropriate information and support services for spouses of people with YOD that help them cope with changes in their relationship (Holdsworth and McCabe, 2018). In LOD, behavioral changes in persons with LOD have been associated with a lower quality of the spousal relationship as perceived by the spouses (de Vugt et al., 2003), while literature on the factors that influence the quality of the spousal relationship in YOD is scarce. Previous studies often used small sample sizes or qualitative data, and most did not specifically target the quality of the relationship itself, but had a broader focus such as describing the general caregiver experiences (Holdsworth and McCabe, 2018). Hence, quantitative studies examining changes in the quality of the relationship over time are needed due to the progressive nature of YOD.

To improve information and support services for spouses of people with YOD, this study aims to determine how the quality of the relationship changes over time and to identify factors that influence the quality of the spousal relationship. Better understanding factors that impact the quality of the relationship may provide clinical possibilities to increase well-being and quality of life as perceived by spousal caregivers (Holdsworth and McCabe, 2018). This may reduce caregiver distress and may help caregivers to better fulfill caregiving tasks. In turn, this may lower the need for professional care and delay the time to institutionalization (Bakker et al., 2013; Miller et al., 2012). In line with previous studies, we hypothesize that spouses of people with YOD may experience deterioration in the perceived quality of the relationship over time due to characteristics of the person with YOD, such as neuropsychiatric symptoms, and also characteristics of the spouse, such as personality and coping strategies.

\section{Methods}

\section{Study design and setting}

The current study used data from the longitudinal two-year cohort of the NEEDs in Young onset Dementia (NeedYD) study (van Vliet et al., 2010a). Persons with YOD and their primary caregiver were recruited between 2007 and 2011 through Dutch memory clinics at Amsterdam and Maastricht, regional hospitals, and mental health services. Additionally, a cohort of participants was recruited through specialized day care facilities affiliated with the Dutch National YOD taskforce. Persons with YOD completed clinical tests and participated in a semi-structured interview at baseline and after $6,12,18$, and 24 months. Spouses also completed a questionnaire and participated in a semi-structured interview at the same time points. This study is reported following the guidelines of STROBE (von Elm et al., 2014).

\section{Participants}

The NeedYD study included 209 persons with YOD and their caregivers. Persons with symptom onset before the age of 65 were included, regardless of their age at which they received a dementia diagnosis. In accordance with the Dutch consensus guidelines (CBO, 2005) and the Diagnostic and Statistical Manual of Mental Disorders American Psychiatry (American Psychiatry Association, 2000), the dementia diagnosis was based on clinical and neuropsychological assessments, in combination with neuroimaging. Diagnosis of dementia subtypes was made in accordance with regular guidelines (Erkinjuntti, 1994; McKeith, 2006; McKhann et al., 1984; Mesulam et al., 2003; Neary et al., 1998). Persons with YOD caused by HIV, traumatic brain injury, Down's syndrome, Huntington's disease, or alcohol abuse were excluded.

In the current study, persons with YOD and their spousal caregiver were included if they were in a 
spousal relationship (dyad), shared the same household, and completed items about the quality of the relationship at a minimum of two different time points.

\section{Primary outcome: The perceived quality of the relationship by spouses over 24 months}

The primary outcome, the perceived quality of the relationship by spouses over 24 months, was quantitatively assessed by four items from the University of Southern California Longitudinal Study of Three-Generation Families measures of positive affect (Lawrence et al., 1998). The four items assess the current level of (1) closeness ("how close do you feel in the relationship between you and your spouse with dementia?"), (2) communication ("how is the communication between you and your spouse with dementia?"), (3) sharing life views ("how similar are your views about life to those of your spouse with dementia?"), and (4) getting along ("how well do you and your spouse with dementia get along together?"). Each item was rated on an ordinal scale $\quad(1=$ not $\quad$ close/well/similar/good at all, $4=$ very close $/$ well $/$ similar $/$ good). In line with Lawrence et al. (1998), we used a sum score as outcome variable (range: 4-16; Cronbach's $\alpha=.71$ ). In addition to the sum score, spouses were also asked at all timepoints to assign a grade $(1=$ not good at all, $10=$ very good) to their current perceived quality of the relationship ("how would you grade your current relationship with your spouse with dementia?"). Assessments were completed at baseline, 6, 12, 18, and 24 months (van Vliet et al., 2010a).

\section{Baseline predictor characteristics of the person with YOD}

In addition to demographic characteristics such as gender and age and dementia diagnosis, the dementia severity $(1=$ no cognitive decline, $7=$ severe dementia) in the person with YOD were assessed at baseline during a semi-structured interview using the Global Deterioration Scale (GDS; Reisberg et al., 1982). In addition, the awareness of deficits ( $1=$ absent awareness, $4=$ intact awareness) in the person with YOD was rated using the Global Rating of Awareness in Dementia (GRAD; Verhey et al., 1993) at baseline.

During the baseline interview with the spouse, the presence $(0=$ no, $1=$ yes $)$, severity $(1=$ minor, $3=$ severe $)$, and frequency $(1=$ less than once a week, $4=$ once or more than once a day) of neuropsychiatric symptoms in the person with YOD were assessed using the Neuropsychiatric Inventory (NPI; Cumming, 1997; Kat et al., 2002). A continuous score per neuropsychiatric symptom was obtained by multiplying severity and frequency scores (range $=0-12$ ). A summed total NPI score (range: 0-144) and four NPI sub-syndrome scores were assessed (Aalten et al., 2008): apathy (sum of apathy, eating abnormalities, range: 0-24), hyperactivity (sum of agitation, euphoria, disinhibition, irritability, aberrant motor behavior, range: 0-60), depression and anxiety (sum of depression and anxiety, range: 0-24), and psychosis (sum of delusions, hallucinations, nighttime disturbances, range: 0-36). During the baseline interview, spouses also completed the Interview for Deterioration in Daily Living Activities (IDDD; Teunisse and Derix, 1997). Spouses rated ( $0=$ never, $4=$ always) whether the person with YOD showed initiative toward (sum of 9 items, range: 0-36) and needed assistance to perform (sum of 11 items, range: 0-44) daily living activities, such as washing oneself, preparing a meal, and handling finances.

\section{Baseline predictor characteristics of the spouse}

In addition to demographic characteristics such as gender and age, spouses completed 12 items ( $1=$ not at all, $5=$ totally agree $)$ of the NEO Personality Inventory (NEO-FFI; Costa and McCrae, 1989) to measure neuroticism. In line with Chapman (2007) and Saucier (1998), two subscales of neuroticism were assessed: negative affect (items 1 , $11,16,31$, and 46) and self-reproach (items 6, 21, $26,36,41,51$, and 56). In addition, spouses completed 47 items $(1=$ never, $4=$ very often) of the Utrechtse Coping List (UCL; Schreurs et al., 1993) to determine spousal coping strategies. Specifically, seven items measured active coping (e.g. clarifying and acting immediately), eight items measured palliative reaction patterns (e.g. diverting attention and engaging in other activities), eight items measured avoidance (e.g. avoiding certain situations), six items measured seeking social support (e.g. looking for comfort from others), five items measured reassuring thoughts (e.g. thinking that worse things can happen), seven items measured passive reaction patterns (e.g. feeling incapable), and three items measured the expression of emotions (e.g. expressing anger and frustration).

\section{Data analysis}

To test for change over time in the two primary outcomes (sum score and grade) of perceived quality of the relationship, separate linear mixed models (LMMs) were used. The fixed effect of the continuous time variables gives the average change in quality of the relationship per six months.

To evaluate associations between the baseline predictor variables and levels of the perceived quality 
of the relationship, averaged over 24 months, each baseline predictor characteristic was separately added to the LMMs. Separately for each baseline predictor characteristic, a fixed effect was included. Subsequently, the LMMs were extended with an interaction effect time*predictor to test whether change over time in relationship quality was influenced by the predictor. For each LMM, model fit was examined by likelihoodtesting $\left(X^{2}, p<.05\right)$, which compared the maximum loglikelihood $(-2 L L)$ and the degrees of freedom $(d f)$ of the nested models. Random intercept and random slope models with an unstructured correlation matrix were used as this gave best fit.

To gain insight into how the four individual items of the sum score changed over 24 months, General Estimation Equation (GEE) models were constructed using the individual items as dependent variables. GEE models were preferred over LMMs due to the skewed distribution and ordinal measurement level of the individual items on closeness, communication, sharing life views, and getting along. While both approaches are suitable for repeated measures and give largely similar estimates for continuous outcomes, the individual-specific LMM model can differ from the marginal GEE model when the dependent variable is categorical, with the latter being appropriate if one is interested in population-average change (the regression estimate) and less in the individual-specific (random effect) part (Heck et al., 2012; Twisk, 2007). In the GEE models, time was included as a predictor variable to indicate change over 24 months. An independent correlation matrix was specified for the GEE models.

All analyses were conducted in SPSS 25.0. An alpha level of .05 (in two-sided tests) was used, and a $p$-value of $<.05$ was considered to reflect statistical significance.

\section{Ethical considerations}

The NeedYD-study protocol was approved by the Medical Ethics Committee of Maastricht University Medical Center (MEC 07-2-38), the Netherlands.

\section{Results}

\section{Participants}

Of the initial 209 dyads, 178 were eligible for inclusion. Ten dyads were excluded because the spouse did not complete items about the quality of the relationship at two different time points. No differences were found regarding baseline predictor variables or outcome variables, except for the excluded spouses who reported more symptoms of psychosis in the person with YOD.

In total, 102 males and 76 females with YOD were included, with an average age of 61.6 years $(\mathrm{SD}=5.3)$ at baseline (Table 1). On average, symptom-onset started 7.4 years $(\mathrm{SD}=3.9)$ before inclusion. Alzheimer's dementia (59.6\%) was the most prevalent diagnosis of YOD, followed by frontotemporal dementia (FTD) (19.1\%) and vascular dementia (11.2\%). Of the spouses, 75 were male and 103 female (including two female-female and one male-male dyad), with an average age of 60.5 years $(\mathrm{SD}=6.8)$ at baseline.

The averaged sum score for the quality of the relationship was $10.7(\mathrm{SD}=2.4)$ at baseline and 9.8 $(\mathrm{SD}=2.3)$ after 24 months. Spouses graded the relationship quality as merely satisfactory with a $6.4(\mathrm{SD}=2.14)$ at baseline and $6.0(\mathrm{SD}=2.36)$ after 24 months.

\section{The perceived quality of the relationship by spouses over time}

To indicate change in the sum score and the grade for the perceived quality of the relationship over 24 months (Table 2), two LMMs were constructed (Table 3). A linear decline in both the sum score for the quality of the relationship (slope $=-.038$, $p<.001)$ and the grade for the quality of the relationship (slope $=-.020, p<.001$ ) was observed over 24 months. In-depth analyses at item-level using GEE indicated that experienced feelings of emotional closeness, satisfaction with communication, and satisfaction with sharing views deteriorated over 24 months. The item regarding getting along well did not significantly increase or decrease over 24 months (Table 4).

\section{Baseline characteristics as a predictor of perceived quality of the relationship by spouses}

Baseline characteristics of the person with YOD were separately added as predictors to the LMMs to examine their predictive value regarding the perceived quality of the relationship over 24 months. A lower sum score for quality of the relationship was associated with a higher total NPI score, higher levels of apathy, higher levels of hyperactivity, a presence of FTD, symptom duration, and lower levels of awareness in the person with YOD. All these baseline variables were also associated with a lower grade for the quality of the relationship over 24 months (Table 5). In addition, the sum score for the perceived quality of the relationship by spouses was associated to a lower level of initiative toward performing daily living activities in people with 
Table 1. Baseline characteristics of persons with YOD and their spouses $(n=178)$

\begin{tabular}{|c|c|c|}
\hline & $\begin{array}{l}\text { PERSONS } \\
\text { WITH YOD }\end{array}$ & SPOUSES \\
\hline Gender, $N$ (male/female) & $102 / 76$ & $75 / 103$ \\
\hline Age in years, mean (SD) & $61.6(5.3)$ & $60.5(6.8)$ \\
\hline $\begin{array}{l}\text { Symptom duration before } \\
\text { baseline in years, mean (SD) }\end{array}$ & $7.4(3.9)$ & \\
\hline \multicolumn{3}{|l|}{ Diagnosis, $\mathrm{N}(\%)$} \\
\hline - Alzheimer's dementia & $106(59.6)$ & \\
\hline - Frontotemporal dementia & $34(19.1)$ & \\
\hline - Vascular dementia & $20(11.2)$ & \\
\hline - Lewy body dementia & $6(3.4)$ & \\
\hline $\begin{array}{l}\text { - Mixed Alzheimer/vascular } \\
\text { dementia }\end{array}$ & $6(3.4)$ & \\
\hline - Not otherwise specified & $6(3.4)$ & \\
\hline GDS, mean (SD) & $4.5(1.0)$ & \\
\hline GRAD, mean (SD) & $2.6(.96)$ & \\
\hline \multicolumn{3}{|l|}{ IDDD, mean (SD) } \\
\hline $\begin{array}{l}\text { - Initiative toward daily living } \\
\text { activities }\end{array}$ & $15.0(10.1)$ & \\
\hline $\begin{array}{l}\text { - Performance of daily living } \\
\text { activities }\end{array}$ & $20.2(13.6)$ & \\
\hline \multicolumn{3}{|l|}{$\mathrm{NPI}^{1}$, mean $(\mathrm{SD})$} \\
\hline - Total & $25.8(18.9)$ & \\
\hline - Hyperactivity $(n=138)$ & $13.3(10.6)$ & \\
\hline - Apathy $(n=139)$ & $10.3(6.6)$ & \\
\hline - Psychosis $(n=68)$ & $6.4(6.3)$ & \\
\hline $\begin{array}{l}\text { - Depression and anxiety } \\
\quad(n=120)\end{array}$ & $5.5(5.1)$ & \\
\hline \multicolumn{3}{|l|}{ Neuroticism, mean (SD) } \\
\hline - Self-reproach & & $15.5(5.0)$ \\
\hline - Negative affect & & $14.0(4.1)$ \\
\hline \multicolumn{3}{|l|}{ UCL, mean (SD) } \\
\hline - Active coping & & $18.4(3.7)$ \\
\hline - Palliative reaction pattern & & $16.7(3.2)$ \\
\hline - Avoidance & & $15.3(3.2)$ \\
\hline - Seeking social support & & $12.6(3.1)$ \\
\hline - Reassuring thoughts & & $11.7(2.5)$ \\
\hline - Passive reaction pattern & & $11.2(3.3)$ \\
\hline - Expressing emotions & & $5.4(1.5)$ \\
\hline
\end{tabular}

${ }^{1}$ Only scores $\geq 1$ were used to compute average NPI subsyndrome scores. GDS, Global Deterioration Scale; GRAD, Global Rating of Awareness in Dementia; IDDD, Interview for Deterioration in Daily Living Activities using domain scores for initiative; NPI, Neuropsychiatric Inventory; Neuroticism = NEO-FFI; UCL, Utrechtse Coping List, using active coping.

YOD. A lower grade for the quality of the relationship over 24 months was also associated with higher levels of depression and anxiety in persons with YOD.

When adding interaction effects between time and the baseline predictor variables of the person with YOD to the LMMs, the association between the total NPI score in the person with YOD and the sum score for quality of the relationship significantly diminished over 24 months (slope $=.005, p=.007$ ).
The associations between apathy and the sum score for the quality of the relationship (slope $=.017$, $p<.001)$ and hyperactivity and the sum score for the quality of the relationship (slope $=.016$, $p<.001)$ also significantly diminished over 24 months. No significant interaction effects between time and other baseline predictor variables of the person with YOD were found.

Next, in separate LMMs, the baseline characteristics of the spouses were added as predictors to the LMMs. The sum score for the quality of the relationship over 24 months was associated with the spouses' palliative and passive reaction patterns. This coping style was also associated to a lower grade for the quality of the relationship over 24 months. More expression of emotions and more seeking of social support by spouses were also associated to a lower grade for the quality of the relationship. In addition, a higher level of negative affect in spouses was associated to a lower sum score for the quality of the relationship. In addition, a lower grade was associated to higher levels of selfreproach in the spouse, but this effect diminished over 24 months due to a significant interaction effect with time (slope $=.016, p<.047$ ). No other significant interaction effects between time and baseline predictor variables of the spouse were found.

\section{Discussion}

This relatively large longitudinal study showed that on average, spouses of people with YOD grade their relationship quality as merely satisfactory as they grade the relationship with a six on a scale between one and ten. Over 24 months, the perceived quality of the relationship was found to deteriorate in general. Higher levels of apathy, higher levels of hyperactivity, a presence of FTD, symptom duration, lower levels of awareness of deficits, lower levels of initiative toward performing daily living activities, and higher levels of depression and anxiety in the person with YOD were associated with a lower perceived quality of the relationship by the spouse. In addition, a coping style characterized by palliative and passive reaction patterns, seeking for social support, and the expression of emotions in the spouse was associated to a lower perceived quality of the relationship. Higher levels of neuroticism (both self-reproach and negative affect) were also associated to a lower quality of the relationship.

\section{Interpretation}

Our quantitative results correspond with previous qualitative findings (Kimura et al., 2015; Lockeridge and Simpson, 2013; Massimo et al., 2013; Riedijk 
Table 2. Descriptive data of the items measuring perceived quality of the relationship over 24 months

\begin{tabular}{|c|c|c|c|c|c|}
\hline & BASELINE & 6 MONTHS & 12 MONTHS & 18 MONTHS & 24 MONTHS \\
\hline Relationship grade, mean (SD) & $6.4(2.14)$ & $6.1(2.33)$ & $6.1(2.36)$ & $6.0(2.5)$ & $6.0(2.36)$ \\
\hline Relationship sum score, mean (SD) & $10.7(2.4)$ & $10.2(2.4)$ & $9.9(2.4)$ & $9.8(2.3)$ & $9.8(2.3)$ \\
\hline \multicolumn{6}{|l|}{ Closeness, \% } \\
\hline - Not at all & 1.1 & 1.7 & 1.8 & 3.6 & 1.9 \\
\hline - Somewhat & 11.9 & 13.3 & 13.1 & 15.7 & 15.5 \\
\hline - Fairly & 21.6 & 30.6 & 35.7 & 36.1 & 37.9 \\
\hline - Very & 65.3 & 54.3 & 49.4 & 44.6 & 44.7 \\
\hline \multicolumn{6}{|l|}{ Communication, \% } \\
\hline - Not at all & 37.0 & 54.0 & 51.8 & 56.0 & 59.0 \\
\hline - Somewhat & 41.0 & 31.4 & 32.1 & 32.5 & 28.0 \\
\hline - Fairly & 18.5 & 14.0 & 13.1 & 9.0 & 11.2 \\
\hline - Very & 3.5 & 4.7 & 3.0 & 2.4 & 1.9 \\
\hline \multicolumn{6}{|l|}{ Sharing views, \% } \\
\hline - Not at all & 28.2 & 43.2 & 46.1 & 48.5 & 46.5 \\
\hline - Somewhat & 26.0 & 30.8 & 29.7 & 30.3 & 31.4 \\
\hline - Fairly & 36.6 & 23.1 & 20.0 & 16.4 & 18.9 \\
\hline - Very & 5.2 & 3.0 & 4.2 & 4.8 & 3.1 \\
\hline \multicolumn{6}{|l|}{ Getting along, \% } \\
\hline - Not at all & 3.4 & 3.5 & 3.6 & 4.3 & 3.1 \\
\hline - Somewhat & 13.2 & 15.2 & 16.1 & 11.1 & 13.7 \\
\hline - Fairly & 36.2 & 44.4 & 42.7 & 43.8 & 44.1 \\
\hline - Very well & 47.1 & 36.8 & 38.7 & 40.7 & 39.1 \\
\hline
\end{tabular}

This table represents valid percentage of scores on the four ordinal items of the University of Southern California Longitudinal Study of

Three-Generation Families measures of positive affect.

Table 3. Change in the perceived quality of the relationship over 24 months

\begin{tabular}{|c|c|c|c|c|c|c|}
\hline & \multicolumn{3}{|c|}{ RELATIONSHIP SUM SCORE } & \multicolumn{3}{|c|}{ RELATIONSHIP GRADE } \\
\hline & ESTIMATE & SIG. & $95 \% \mathrm{CI}$ & ESTIMATE & SIG. & $95 \% \mathrm{CI}$ \\
\hline Linear time effect & -.128 & .003 & -.213 to -.043 & -.09 & .047 & -.185 to -.001 \\
\hline Quadratic time effect & .007 & .125 & -.002 to .016 & .007 & .162 & -.003 to .017 \\
\hline Cubic time effect & -.001 & .226 & -.001 to .001 & -.001 & .224 & -.001 to .001 \\
\hline
\end{tabular}

Significant time effects are displayed in bold. Linear time $=0,6,12,18$, and 24 months. Quadratic time $=$ time* time. Cubic time $=$ time*time* time.

et al., 2008) and the review of Holdsworth and McCabe (2018) that spouses of people with YOD perceive a statistically significant deterioration in the quality of the relationship over time. However, in our study, the absolute average deterioration was relatively small and relationship quality was still graded as merely satisfactory over the course of the disease. Indeed, previous research indicates that spouses of persons with YOD often report to still love their husband or wife (Massimo et al., 2013), were able to get along with the person with YOD, and experience relatively high levels of emotional closeness, similar to spouses of persons with LOD (de Vugt et al., 2003; Riedijk et al., 2008). However, several characteristics of persons with YOD and spouses were associated to a lower quality of the relationship. For example, neuropsychiatric symptoms such as apathy and hyperactivity can be difficult to understand for spouses (Ducharme et al., 2013; Massimo et al., 2013; Paton et al., 2004). In previous qualitative research, caregivers acknowledged to miss their comrade due to apathy and experienced a decline in reciprocity in the person with YOD (de Vugt et al., 2003; Millenaar et al., 2017). Hyperactivity is characterized by agitation, euphoria, disinhibition, irritability, and aberrant motor behavior. These symptoms may cause inappropriate behavior of the person with YOD and result in anger in the spouse that diminishes the quality of the relationship (Massimo et al., 2013).

In contrast with previous research on LOD (de Vugt et al., 2003), in our study, hyperactivity 
Table 4. General estimation equation: change on individual items of the sum score for perceived quality of the relationship by spouses over 24 months

\begin{tabular}{|c|c|c|c|}
\hline & ESTIMATE & SIG. & $95 \% \mathrm{CI}$ \\
\hline \multicolumn{4}{|l|}{ Closeness } \\
\hline Linear time & -.026 & $<.001$ & -.038 to -.014 \\
\hline \multicolumn{4}{|c|}{ Communication } \\
\hline Linear time & -.035 & $<.001$ & -.049 to -.021 \\
\hline \multicolumn{4}{|l|}{ Sharing views } \\
\hline Linear time & -.020 & .001 & -.032 to -.008 \\
\hline \multicolumn{4}{|l|}{ Getting along } \\
\hline Linear time & -.009 & .150 & -.020 to .003 \\
\hline
\end{tabular}

The four ordinal items of the University of Southern California Longitudinal Study of Three-Generation Families measures of positive affect are presented. Significant time effects are displayed in bold.

in persons with YOD was associated to a lower quality of the relationship by the spouses. The higher prevalence of FTD in our younger sample might explain why hyperactivity was associated to a lower quality of the relationship because FTD is characterized by stereotypical behaviors, disinhibition, and more distress related to neuropsychiatric symptoms (Bozeat et al., 2000; de Vugt et al., 2006). Next, a diagnosis of FTD and a lower level of deficit awareness by the person with YOD were also associated to a lower quality of the relationship perceived by the spouse. This confirms earlier findings that a lack of disease awareness in the person with YOD is linked to a lower quality of life in caregivers (Baptista et al., 2016) and more unmet needs and difficulties to arrange care and support by caregivers (Millenaar et al., 2017). A lower quality of the relationship was also associated to lower levels of initiative toward daily living activities in the person with YOD. In contrast, the assistance a person with YOD required in order to perform daily living activities was not associated to the quality of the relationship. It is conceivable that spouses have more understanding for the inability to perform daily living activities in a person with YOD and are less understanding of the lack of initiative toward daily living activities. A lack of initiative in persons with YOD can be difficult to understand for spouses because it is not often attributed to dementia (Paton et al., 2004). As a result, spouses might blame the person with YOD for not showing enough initiative.

Subsequently, a higher level of self-reproach in the spouse was associated to a lower quality of the relationship by the spouse. Self-reproach, a subdomain of neuroticism, includes feelings of inferiority, worthlessness, helplessness, and being ashamed (Chapman, 2007). Previous research has shown that dementia caregivers with higher levels of neuroticism more often apply nonadaptive coping strategies (de Vugt et al., 2004). The use of these nonadaptive coping strategies might result in a higher burden, more frustration, and perhaps more relational conflict. This could explain why spouses who experience higher levels of selfreproach report a lower quality of the relationship. In addition, palliative and passive reacting patterns used by spouses were associated to a lower quality of the relationship. Surprisingly, seeking social support and the expression of emotions by spouses were also associated to a lower quality of the relationship. This might be due to reversed causality. Spouses who perceive the quality of their relationship as low might seek more social support from friends and relatives to express their emotions and cope with the situation (Knippenberg et al., 2018; Lockeridge and Simpson, 2013).

System theory might provide a framework to better understand the complex interactions and interrelationships between aspects of the spousal relationship and YOD. Dementia is known to influcence the emotional connection between the person with dementia and caregivers (Chapman et al., 2019). As social relationships are continuously redefined, a loss in the emotional connection with the person with YOD may deteriorate the quality of the relationship perceived by spousal careivers. Over time, spouses might learn to come to terms with the situation and develop a positive attitude toward their caregiving role (Lloyd et al., 2016). A positive attitude toward the caregiving role and the development of an adaptive coping strategy might help spouses to cope with changes in their relationship (Lockeridge and Simpson, 2013). This might explain why spouses of people with YOD were found to feel relatively satisfied with regard to their emotional closeness and getting along.

The development of a more positive attitude toward the caregiving role or an adaptive coping strategy might explain why the influence of apathy and hyperactivity in the person with YOD diminished over time. Another explanation for the diminishing influence of apathy and hyperactivity might be that we only used baseline measurements of these predictor variables. The progressive nature of YOD and the fluctuating course of neuropsychiatric symptoms might have weakened the association between the baseline predictors and perceived quality of the relationship over time.

\section{Strengths and limitations}

A diverse population of people with YOD and their relatives was followed over time and the longitudinal design with repeated assessments allowed us to investigate changes in the quality of the relationship over time and identify factors that are associated to 
Table 5. Linear mixed models: predictors of the perceived quality of the relationship by spouses over 24 months

\begin{tabular}{|c|c|c|c|c|c|c|}
\hline \multirow[b]{2}{*}{ BASELINE PREDICTOR VARIABLE } & \multicolumn{3}{|c|}{ RELATIONSHIP SUM SCORE } & \multicolumn{3}{|c|}{ RELATIONSHIP GRADE } \\
\hline & ESTIMATE & SIG. & $95 \% \mathrm{CI}$ & ESTIMATE & SIG. & $95 \% \mathrm{CI}$ \\
\hline \multicolumn{7}{|c|}{ Baseline predictor variables of the person with YOD } \\
\hline Age & -.034 & .233 & -.091 to .022 & -.038 & .168 & -.093 to .016 \\
\hline Presence of FTD & -.871 & .025 & -1.629 to -.113 & -.750 & .044 & -1.479 to -.021 \\
\hline Symptom duration & -.558 & $<.001$ & -.850 to -.265 & -.430 & .003 & -.715 to -.145 \\
\hline Dementia severity & -.255 & .099 & -.559 to .049 & -.191 & .193 & -.480 to .098 \\
\hline Awareness of deficits & .717 & $<.001$ & .430 to 1.004 & .464 & .001 & .183 to .746 \\
\hline Initiative toward daily living activities & .310 & .042 & .012 to .608 & .133 & .366 & -.157 to .424 \\
\hline Performance in daily living activities & -.167 & .276 & -.469 to .134 & -.008 & .955 & -.299 to .283 \\
\hline NPI total score & -.053 & $<.001$ & -.069 to -.037 & -.038 & $<.001$ & -.052 to -.025 \\
\hline NPI total*time & .005 & .007 & .002 to .010 & & & \\
\hline Hyperactivity & -.956 & $<.001$ & -1.274 to -.638 & -.721 & $<.001$ & -.993 to -.450 \\
\hline Hyperactivity*time & .016 & .016 & .003 to .030 & & & \\
\hline Apathy & -1.069 & $<.001$ & -1.376 to -.762 & -.701 & $<.001$ & -.972 to -.430 \\
\hline Apathy*time & .017 & .010 & .004 to .030 & & & \\
\hline Psychosis & -.015 & .921 & -.317 to .286 & -.062 & .674 & -.353 to .228 \\
\hline Depression and anxiety & -.290 & .057 & -.590 to .009 & -.302 & .040 & -.589 to -.014 \\
\hline \multicolumn{7}{|l|}{ Baseline predictor variables of the spouse } \\
\hline Gender & -.548 & .076 & -1.154 to .059 & -.566 & .056 & -1.148 to .015 \\
\hline Age & -.016 & .488 & -.060 to .029 & -.020 & .358 & -.063 to .023 \\
\hline Self-reproach & -.548 & $<.001$ & -.841 to -.255 & -.567 & $<.001$ & -.876 to -.258 \\
\hline Self-reproach*time & & & & .016 & .047 & .001 to .031 \\
\hline Negative affect & -.366 & .017 & -.667 to -.065 & -.231 & .118 & -.520 to .059 \\
\hline Active coping & -.141 & .365 & -.448 to .165 & .088 & .556 & -.207 to .383 \\
\hline Palliative reacting & -.537 & $<.001$ & -.836 to -.238 & -.404 & .006 & -.692 to -.115 \\
\hline Avoidance & -.190 & .215 & -.493 to .112 & -.151 & .307 & -.442 to .140 \\
\hline Seeking social support & -.281 & .064 & -.577 to .016 & -.370 & .012 & -.658 to -.082 \\
\hline Reassuring thoughts & -.025 & .868 & -.327 to .276 & .203 & .170 & -.088 to .494 \\
\hline Passive reacting & -.427 & .005 & -.725 to -.129 & -.325 & .027 & -.614 to -.037 \\
\hline Expression of emotions & -.286 & .063 & -.587 to .016 & -.529 & $<.001$ & -.881 to -.248 \\
\hline
\end{tabular}

Each baseline predictor variable was added and analyzed separately in the linear mixed models. The linear mixed models with lowest $-2 \mathrm{LL}$ are reported. All reported estimates represent standardized effects. Significant effects are displayed in bold.

the quality of the relationship. Our study findings correspond with previous and international literature, which increases the likelihood of external validity and generalizability.

Although we intended to examine predictors of perceived quality of the relationship over time, the associations we found could be bidirectional. In terms of causality, this means that a lower relationship quality can also influence, for example, the behavior of the person with YOD or coping mechanisms of the spouse. Also, some of the effects might have occurred prior to inclusion while other effects might still occur after the 24-month follow-up.

In addition, there seems to be a lack of validated measurement tools to examine the quality of the relationship in a person with dementia and their spouse. In this study, we could not explore the perceived quality of the relationship as it was experienced by the person with YOD, as in the NeedYD study only the spouse provided information about the quality of the relationship. The quality of the relationship experienced by the person with YOD might influence their behavior and thus have an effect on the perceived quality of the relationship by the spouse. Future studies that examine the quality of the relationship should take the view of the person with YOD into account.

The use of multiple statistical tests in our study increased the risk of a type 1 error. However, the results of our explorative study correspond with previous qualitative literature results (Holdsworth and McCabe, 2018), which creates a certain degree of confidence in the conclusions presented here.

\section{Practical implications}

Our findings can tailor interventions aimed at maintaining or improving the quality of the relationship in couples with YOD. Departing from a social perspective on health, persons with YOD and their spouses can still experience well-being and a high quality of life (Huber et al., 2011; de Vugt and Dröes 2016). Helping spouses to accept or come to terms 
with factors that threaten their sense of couplehood may help them to develop a more positive attitude toward their spousal relationship and improve the quality of the relationship and care.

\section{Conclusion}

This study revealed that spouses of people with YOD experience a deterioration in their perceived quality of the relationship over 24 months. This deterioration was found to occur in various relationship domains and was associated with a broad set of characteristics of both the person with YOD and the spouse. Our findings can tailor interventions aimed at maintaining or improving the quality of the relationship in couples with YOD.

\section{Conflict of interest}

None.

\section{Description of authors' roles}

J. Bruinsma conducted the analyses and wrote the paper in close collaboration with K. Peetoom, S. Köhler, J. Millenaar, F. Verhey, and M. de Vugt. Other authors had a substantial contribution to the design and data collection of the NeedYD study and critically revised this manuscript.

\section{References}

Aalten, P. et al. (2008). Consistency of neuropsychiatric syndromes across dementias: results from the European Alzheimer Disease Consortium. Part II. Dementia and Geriatric Cognitive Disorders, 25, 1-8. doi: 10.1159/000111082.

American Psychiatry Association. (2000). Diagnostic and Statistical Manual of Mental Disorders DSM-IV-TR (Tekst Revision). Washington, DC: Americal Psychiatry Association.

Bakker, C. et al. (2013). Predictors of the time to institutionalization in young- versus late-onset dementia: results from the needs in Young Onset Dementia (NeedYD) study. Fournal of the American Medical Directors Association, 14, 248-253. doi: 10.1016/j.jamda.2012.09.011.

Baptista, M. A. et al. (2016). Quality of life in young onset dementia: an updated systematic review. Trends Psychiatry and Psychotherapy, 38, 6-13. doi: 10.1590/2237-60892015-0049.

Bozeat, S., Gregory, C. A., Lambon Ralph, M. A. and Hodges, J. R. (2000). Which neuropsychiatric and behavioural features distinguish frontal an dtemporal variants of frontotemporal dementia from Alzheimer's disease? Fournal of Neurology, Neurosurgery, and Psychiatry, 69, 178-186. doi: 10.1136/jnnp.69.2.178.
CBO. (2005). Guideline Diagnosis and Pharmacological Treatment of Dementia. Alphen aan den Rijn: Van Zuiden Communications B.V.

Chapman, B. P. (2007). Bandwidth and fidelity on the NEOFive Factor Inventory: replicability and reliability of Saucier's (1998) item cluster subcomponents. Fournal of Personality Assessment, 88, 220-234. doi: 10.1080/0022389070 1268082.

Chapman, M., Philip, J. and Komesaroff, P. (2019). Towards an ecology of dementia: a manifesto. Fournal of Bioethical Inquiry, 16, 209-216. doi: 10.1007/s11673-01909910-8.

Costa, P. T. and McCrae, R. R. (1989). The NEO-PI/NEOFFI Manual Supplement. Odessa: Psychological Assessment Resources.

Cummings, J. L. (1997). The neuropsychiatric inventoryassessing psychopathology in dementia patients. Neurology, 48, S10-S16.

de Vugt, M. E. and Dröes, R-M. (2016). Social health in dementia. Towards a positive dementia discourse. Aging $\mathcal{E}$ Mental Health, 21. doi: 10.1080/13607863 .2016 .1262822 .

de Vugt, M. E. et al. (2003). Behavioural disturbances in dementia patients and quality of the marital relationship. International fournal of Geriatric Psychiatry, 18, 149-154. doi: 10.1002/gps.807.

de Vugt, M. E. et al. (2004). Do caregiver management strategies influence patient behaviour in dementia? International fournal of Geriatric Psychiatry, 19, 85-92. doi: $10.1002 /$ gps.1044.

de Vugt, M. E. et al. (2006). Impact of behavioural problems on spousal caregivers: a comparison between Alzheimer's disease and frontotemporal dementia. Dementia and Geriatric Cognitive Disorders, 22, 35-41. doi: 10.1159/000093102.

Draper, B. and Withall, A. (2016). Young onset dementia. International Medicine fournal, 46, 779-786. doi: 10.1111/imj.13099.

Ducharme, F., Kergoat, M.-J., Antoine, P., Pasquier, F. and Coulombe, R. (2013). The unique experience of spouses in early-onset dementia. American fournal of Alzheimer's Disease E Other Dementias, 28, 634-641. doi: 10.1177/1533317513494443.

Erkinjuntti, T. (1994). Clinical criteria for vascular dementia: the NINDS-AIREN criteria. Dementia, 5, 189-192. doi: 10.1159/000106721.

Holdsworth, K. and McCabe, M. (2018). The impact of younger-onset dementia on relationships, intimacy, and sexuality in midlife couples: a systematic review. International Psychogeriatrics, 30, 15-29. doi: 10.1017/S1041610217001806.

Heck, R. H., Thomas, S. L. and Tabata, L. N. (2012). Multilevel Modeling of Categorical Outcomes Using IBM SPSS. New York: Taylor \& Francis Group.

Huber, M. et al. (2011). Health how should we define it? BMF, 343, 235-237 doi: 10.1136/bmj.d4163.

Kat, M. G., de Jonghe, J. F. M., Aalten, P., Kalisvaart, C. J., Dres, R. M. and Verhey, F. R. J. (2002). Neuropsychiatrische symptomen bij dementie: Psychometrische aspecten van de Nederlandse Neuropsychiatric Inventory (NPI). Tijdschrift voor Gerontologie en Geriatrie, 33, 150-155. 
Kimura, N. R., Maffioletti, V. L., Santos, R. L., Baptista, M. A. and Dourado, M. C. (2015). Psychosocial impact of early onset dementia among caregivers. Trends Psychiatry and Psychotherapy, 37, 213-219. doi: 10.1590/2237-6089-2015-0038.

Knippenberg, R. J. M., de Vugt, M. E., Ponds, R. W., Verhey, F. R. J. and Myin-Germeys, I. (2018). Emotional reactivity to daily life stress in spousal caregivers of people with dementia: an experience sampling study. PLos One, 13, 1-15. doi: 10.1371/journal.pone.0194118.

Lawrence, R. H., Tennstedt, S. L. and Assmann, S. F. (1998). Quality of the caregiver-care recipient relationship: does it offset negative consequences of caregiving for family caregivers? Psychology and Aging, 13, 150-158. doi: 10.1037//0882-7974.13.1.150.

Lloyd, J., Patterson, T. and Muers, J. (2016) The positive aspects of caregiving in dementia: a critical review of qualitative literature. Dementia, 15, 1534-1561. doi: $10.1177 / 1471301214564792$.

Lockeridge, S. and Simpson, J. (2013). The experience of caring for a partner with young onset dementia: how younger carers cope. Dementia, 12, 635-651. doi: 10.1177 /1471301212440873.

Massimo, L., Evans, L. K. and Benner, P. (2013). Caring for loved ones with frontotemporal degeneration: the lived experiences of spouses. Geriatric Nursing, 34, 302-306. doi: 10.1016/j.gerinurse.2013.05.001.

McKeith, I. G. (2006). Consensus guidelines for the clinical and pathologic diagnosis of dementia with Lewy bodies (DLB): report of the consortium on DLB international workshop. Fournal of Alzheimer's Disease, 9, 417-423. doi: 10.3233/jad-2006-9s347.

McKhann, G., Drachman, D., Folstein, M., Katzman, R., Price, D. and Stadlan, E. M. (1984). Clinical diagnosis of Alzheimer's disease: report of the NINCDS-ADRDA work group under the auspices of department of health and human services task force on Alzheimer's Disease. Neurology, 34, 939-944. doi: 10.1212/wnl.34.7.939.

Mesulam, M. M., Grossman, M., Hillis, A., Kertesz, A. and Weintraub, S. (2003) The core and halo of primary progressive aphasia and semantic dementia. Annals of Neurology, 54, S11-14. doi: 10.1002/ana.10569.

Millenaar, J. K. et al. (2017). Exploring perspectives of young onset dementia caregivers with high versus low unmet needs. International fournal of Geriatric Psychiatry, 33, 340-347. doi: 10.1002/gps.4749.

Miller, E. A., Rosenheck, R. A. and Schneider, L. S. (2012). Caregiver burden, health utilities, and institutional service use in Alzheimer's disease. International journal of Geriatric Psychiatry, 27, 382-393. doi: 10.1002/gps.2730.

Neary, D. et al. (1998). Frontotemporal lobar degeneration: a consensus on clinical diagnostic criteria. Neurology, 51, 1546-1554. doi: 10.1212/wnl.51.6.1546.

Paton, J., Johnston, K., Katona, C. and Livingston, G. (2004). What causes problems in Alzheimer's disease: attributions by caregivers. A qualitative study. International
Fournal of Geriatric Psychiatry, 19, 527-532. doi: 10.1002 /gps.1118.

Reisberg, B., Ferris, S. H., de Leon, M. J. and Crook, T. (1982). The global deterioration scale for assessment of primary degenerative dementia. American fournal of Psychiatry, 139, 1136-1139. doi: 10.1176/ajp. 139.9.1136.

Riedijk, S., Duivenvoorden, H., Rosso, S., Van Swieten, J., Niermeijer, M. and Tibben, A. (2008). Frontotemporal dementia: change of familial caregiver burden and partner relation in a Dutch cohort of 63 patients. Dementia and Geriatric Cognitive Disorders, 26, 398-406. doi: 10.1159/000164276.

Saucier, G. (1998). Replicable item-cluster subcomponents in the NEO Five-Factor Inventory. Fournal of Personality Assessment, 70, 263-276. doi: 10.1207/s15327752jpa7002_6.

Schreurs, P. J. G., van de Willige, G., Brosschot, J. F., Tellegen, B. and Graus, G. M. H. (1993). De Utrechtse Coping Lijst: UCL. Lisse: Swets en Zeitlinger.

Teunisse, S. and Derix, M. M. A. (1997). The interview for deterioration in daily living activities in dementia: agreement between primary and secondary caregivers. International Psychogeriatrics, 9, 155-162. doi: 10.1017 /S1041610297004845.

Twisk, J. W. R. (2007). Applied Logitudinal Data Analysis for Epidemiology. Cambridge: Cambridge University Press.

Vangelisti, A. and Perlman, D. (2006). Cambridge Handbook of Personal Relationships. Cambridge: Cambridge University Press.

van Vliet, D., Bakker, C., Koopmans, R. T., VernooijDassen, M. J., Verhey, F. R. and de Vugt, M. E. (2010a). Research protocol of the NeedYD-study (Needs in Young onset Dementia): a prospective Cohort study on the needs and course of early onset dementia. BMC Geriatrics, 10. doi: 10.1186/1471-2318-10-13.

van Vliet, D. et al. (2011). Caregivers' perspectives on the pre-diagnostic period in early onset dementia: a long and winding road. International Psychogeriatrics, 23, 1393-1404. doi: 10.1017/S1041610211001013.

van Vliet, D., de Vugt, M. E., Bakker, C., Koopmans, R. T. and Verhey, F. R. (2010b). Impact of early onset dementia on caregivers: a review. International fournal of Geriatric Psychiatry, 25, 1091-1100. doi: 10.1002/gps.2439.

Verhey, F. R. J., Rozendaal, N., Ponds, R. W. H. M. and Jolles, J. (1993). Dementia, awareness and depression. International fournal of Geriatric Psychiatry, 8, 851-856. doi: 10.1002/gps.930081008.

von Elm, E. et al. (2014). The Strengthening the Reporting of Observational Studies in Epidemiology (STROBE) statement: guidelines for reporting observational studies. International Fournal of Surgery, 12, 1495-1499. doi: 10.1016/j.jclinepi.2007.11.008.

Wawrziczny, E., Antoine, P., Ducharme, F., Kergoat, M. J. and Pasquier, F. (2016). Couples' experiences with early-onset dementie: an interpretative phenomenological analysis of dyadic dynamics. Dementia, 15, 1082-1099. doi: $10.1177 / 1471301214554720$. 